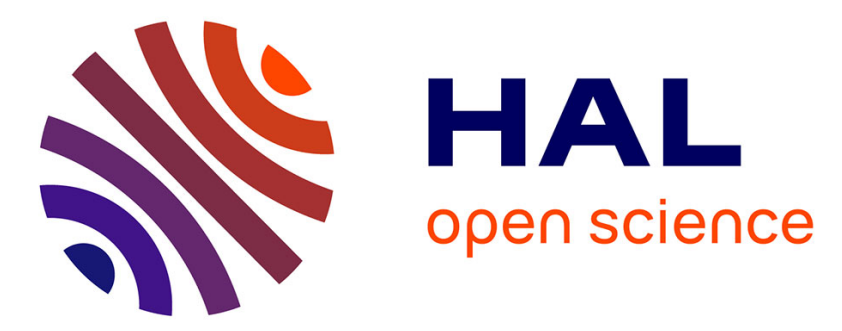

\title{
Dislocations Gliding Study by IR Thermography in C-Mn Steels with Different Solute Atoms Content in the Gigacycle Fatigue Domain
}

Zhiyong Huang, Nicolas Ranc, Danièle Wagner

\section{To cite this version:}

Zhiyong Huang, Nicolas Ranc, Danièle Wagner. Dislocations Gliding Study by IR Thermography in C-Mn Steels with Different Solute Atoms Content in the Gigacycle Fatigue Domain. Key Engineering Materials, 2015, 664, pp.177-187. 10.4028/www.scientific.net/KEM.664.177 . hal-01687127

\section{HAL Id: hal-01687127 \\ https://hal.parisnanterre.fr/hal-01687127}

Submitted on 18 Jan 2018

HAL is a multi-disciplinary open access archive for the deposit and dissemination of scientific research documents, whether they are published or not. The documents may come from teaching and research institutions in France or abroad, or from public or private research centers.
L'archive ouverte pluridisciplinaire HAL, est destinée au dépôt et à la diffusion de documents scientifiques de niveau recherche, publiés ou non, émanant des établissements d'enseignement et de recherche français ou étrangers, des laboratoires publics ou privés. 


\title{
Dislocations gliding study by IR thermography in C-Mn steels with different solute atoms content in the gigacycle fatigue domain
}

\author{
Zhiyong Huang ${ }^{1, a}$, Nicolas Ranc ${ }^{2, b}$, Danièle Wagner ${ }^{3, c^{*}}$ \\ ${ }^{1}$ Sichuan University, School of Aeronautics and Astronautics, No.29 Jiuyanqiao Wangjiang Road, \\ Chengdu, 610064, China \\ ${ }^{2}$ Arts et Métiers ParisTech, PIMM UMR 8006, 75013 Paris, France, \\ ${ }^{3}$ University Paris Ouest Nanterre, Laboratoire LEME, 50 rue de Sèvres, 92410 VILLE D'AVRAY, \\ France \\ ahzyfem@hotmail.com, bnicolas.ranc@ensam.eu, 'daniele.wagner@u-paris10.fr \\ "Corresponding author
}

Keyword: Carbon-manganese steels, gigacycle fatigue tests, infrared camera, dislocations gliding, solute content

\begin{abstract}
Tests were performed on two Carbon-Manganese steels (A42 and A48 steels, French standard) in the gigacycle fatigue domain thanks to a piezoelectric fatigue machine working at $20000 \mathrm{~Hz}$. During the tests, temperature recordings were achieved by an infrared camera for various stress amplitudes. The main difference between the two steels compositions was the aluminum content $(0.045 \%$ for the A42 steel and $0.004 \%$ for the A48 steel), and the carbon content $(0.140 \%$ for the A 42 steel and $0.198 \%$ for the A48 steel). In the A48 steel, the few aluminum content induces a higher free content of solute nitrogen in the lattice. Mechanical spectroscopy tests were performed and gave qualitative results on the solute contents repartition in the lattice. The temperature increase recorded during the fatigue tests for the two steels are different at the beginning of the tests. The differences can be explained by the different repartition of the solute atoms which induces a different dislocation gliding between the two materials. At the end of the tests, the thermal recordings are similar and attributed to the evolution of the solute atoms repartition and the dislocation structure.
\end{abstract}

\section{Introduction}

The fatigue crack mechanism consists in an initiation crack stage (stage I) and a propagation crack stage (stage II) followed by the fast specimen fracture. For materials without inclusions, the crack initiation is always located on the specimen surface whatever the stress amplitude level. For materials with inclusions, the crack initiation site can be located in subsurface on inclusion (or metallurgical heterogeneity) when the stress amplitude decreases in the Very High Fatigue domain.

For a crack initiation located on the specimen surface, the first damage events in the stage I are due to the occurrence of Slips Marks (SM) compared to Persistent Slips Bands (PSB). These PSB are due to the irreversible gliding of dislocations in well oriented grains, leading to intrusions/extrusions. C. Wang et al. [1] have shown that the irreversible PSB occur very early and are correlated to the specific dissipative heat sources [2] leading to a temperature increase during the test. Whatever the frequency (even at very low frequency, stress or strain amplitudes), the selfheating of the specimens occurs. This self-heating can be measure from the temperature field recording on the specimen surface thanks to an infrared camera placed in front of the specimen. For a constant stress amplitude test, firstly the temperature surface increases rapidly, then stabilizes or increases slightly (depending of the stress amplitude level) and finally increases steeply. Higher the stress amplitude level, higher the temperature increase [3]. At low frequency, the thermo-elastic effect can be visualize [4], but at high frequency, this thermo-elastic effect is out of reach. This temperature increase is generated by dissipative heat sources which can be calculated using a local 
expression of the heat diffusion equation [2]. The crack propagation stage is correlated with the rapid increase of the temperature due to the plastic deformation around the crack tip [5].

In this study, fatigue tests on two C-Mn steels with two different solute atoms content in the lattice are performed in the VHCF domain thanks to a piezoelectric fatigue machine working at $20 \mathrm{kHz}$. During the tests, the temperature field was recorded on the specimen surface by an infrared camera. The effect of the solute atoms content on the dislocations gliding is observed by the temperature recording on the specimen surface.

\section{Materials}

The materials studied are two carbon-manganese steels of AFNOR (French standard) NFA 36205 grade A48 and A42 which were received as $40 \mathrm{~mm}$ thick plates. The chemical composition is reported in Table 1. The plates received a prior normalization thermal treatment consisting in austenitizing at $870^{\circ} \mathrm{C}$ then air cooling, leading to a microstructure composed of banded ferrite and pearlite (Fig. 1).

Table 1: Chemical composition (in weight \%) of the tested materials

\begin{tabular}{|c|c|c|c|c|c|c|c|c|c|c|c|c|c|}
\hline Materials & $\mathrm{C}$ & $\mathrm{S}$ & $\mathrm{P}$ & $\mathrm{Si}$ & $\mathrm{Mn}$ & $\mathrm{Ni}$ & $\mathrm{Cr}$ & $\mathrm{Mo}$ & $\mathrm{Cu}$ & $\mathrm{Sn}$ & $\mathrm{Al}$ & $\mathrm{N}$ & $\mathrm{O}$ \\
\hline $\mathrm{A} 42$ & 0,140 & 0,0057 & 0,016 & 0,225 & 0,989 & 0,024 & 0,021 & 0,002 & 0,027 & 0,003 & 0,045 & 0,0082 & 0,0006 \\
\hline $\mathrm{A} 48$ & 0,198 & 0,012 & 0,0104 & 0,207 & 0,769 & 0,135 & 0,095 & 0,025 & 0,273 & 0,023 & 0,004 & 0,0083 & 0,0049 \\
\hline
\end{tabular}

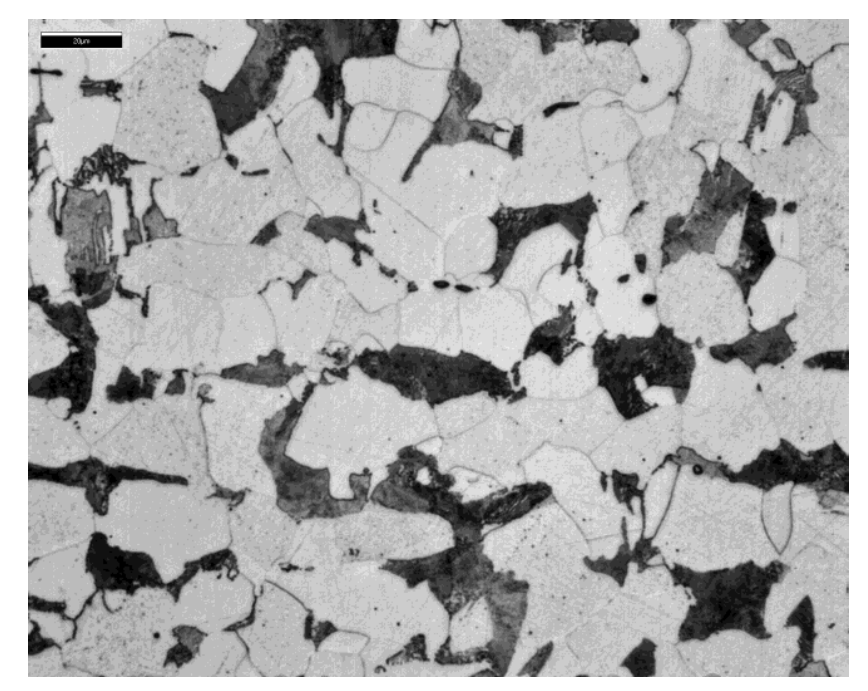

Fig. 1: C-Mn steels microstructure

The A48 grade material is a silicon semi-killed steel containing a very low aluminum content $(0,004 \%)$. This element is in insufficient amount to be capable of trapping nitrogen atoms by aluminum nitride (AIN) formation during cooling from the austenitic domain. Consequently, for this heat a large amount of free nitrogen is still present in the lattice. The A42 grade material is a fullykilled steel containing aluminum content $(0,045 \%)$ and for this amount of aluminum, almost the whole of nitrogen atoms are trapped as aluminum nitrides.

In C-Mn steels, it is well established that the atoms which interact with dislocations are carbon and nitrogen. The location of these atoms is rather complex [6-7]. One part is precipitated in the form of carbides $\left(\mathrm{Fe}_{3} \mathrm{C} \ldots\right)$ or nitrides $\left(\mathrm{Fe}_{4} \mathrm{~N}, \mathrm{Fe}_{16} \mathrm{~N}_{2}\right.$ or $\mathrm{AlN}$ if aluminium is present...). The other part is in solid solution into the centred cubic iron lattice. This part in solid solution is distributed into 3 locations [8-11]: the majority of the atoms gathers and form the "Cotrell atmospheres", a few part segregates on dislocations, and the remaining solute atoms (when all sites near dislocations are 
occupied) are free in the lattice interstitial sites. With the normalization heat treatment for these two steels, very few carbon solute atoms are free in the lattice. The difference between the two steels come essentially from the nitrogen atoms (in great content in the A48 steel)

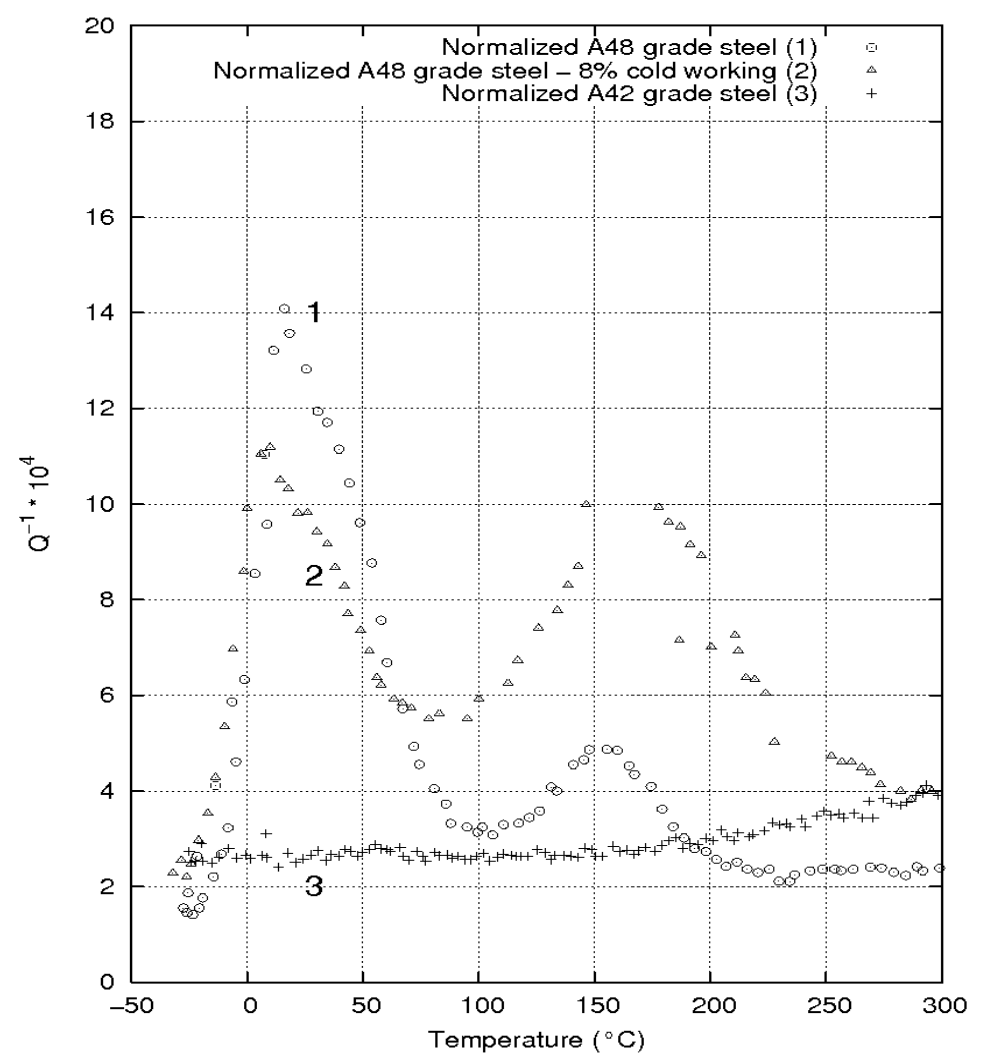

Fig. 2: Internal friction $\mathrm{Q}^{-1}$ versus temperature for $\mathrm{A} 48$ (normalized and cold worked conditions) and A42 steels.

In order to evaluate the balance between carbon and nitrogen atoms free in the lattice and carbon and nitrogen interacting with mobile dislocations, internal friction tests are performed at a frequency of $1,5 \mathrm{kHz}$ on the two materials [12]. The internal friction spectrum measured on the A48 grade reveals two main peaks in the -20 to $300^{\circ} \mathrm{C}$ temperature range (Fig.2, curve 1).

The first one which presents a maximum at about $20^{\circ} \mathrm{C}$ can be associated with the Snoek Peak (SP) resulting from carbon and nitrogen redistribution between octahedral sites in the ferritic lattice. Due to complex interactions between nitrogen and manganese, the Snoek Peak height is not directly proportional to $\mathrm{C}$ and $\mathrm{N}$ interstitial content in the lattice, as observed in pure iron. The second peak, observed in the 150 to $250^{\circ} \mathrm{C}$ temperature range, corresponds to the Cold Work Peak (CWP) and is due to the interaction between dislocations and interstitials such as carbon and nitrogen. The CWP height is related to both the density of mobile dislocations and the interstitial content in the vicinity of dislocations. This classical interpretation of the internal friction spectrum in steels is confirmed by curve 2 which represents the internal friction variation measured on this A48 grade steel after $8 \%$ cold working and one month room temperature aging. In that case, an increase of the CWP with dislocation density is observed, associated with a corresponding SP decrease, in agreement with the classical balance of interstitial atoms between lattice and dislocations [13].

The internal friction spectrum measured on the A42 grade (curve 3) reveals no peak (neither SP peak nor CWP peak) in agreement with the nitrogen content in the ferritic lattice. 


\section{Experimental Procedure}

Tests were performed on a piezoelectric fatigue machine designed by C. Bathias et al.[14].

Specimen (Fig. 3) attachment and piezoelectric fatigue machine constituted the resonance system working at $20 \mathrm{kHz}$. The cyclic loading is tension-compression $(\mathrm{R}=-1)$.

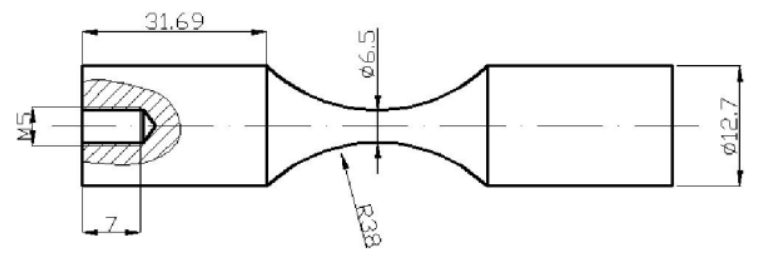

Fig. 3: Specimen design

Firstly, the S-N curve between $10^{6}$ and $10^{9}$ cycles for the two materials was performed (without the temperature recording), using a cooling system to refresh the specimens during the tests.

In order to determine the temperature field on the surface of the specimen, a non-intrusive measurement technique by infrared pyrometer was chosen. In the test, an advanced, high-speed, and high-sensitivity infrared camera from Cedip Infrared Systems, made up of a matrix of 320 x 240 Mercury Cadmium Telluride detectors, was used to record the temperature changes during ultrasonic fatigue tests. The spectral range of the camera is between 3.7 and $4.9 \mu \mathrm{m}$. This method allows the visualization of the temperature field with very good time resolution. In this study, the spatial resolution is $0.17 \mathrm{~mm}$ and the aperture time can vary between $10 \mu \mathrm{s}$ ( 2 cycles) and $1500 \mu \mathrm{s}$ (around 30 cycles) which correspond respectively to a noise of $0.4 \mathrm{~K}$ and $20 \mathrm{mK}$. The acquisition frequency of the camera is between $0.83 \mathrm{~Hz}$ and $100 \mathrm{~Hz}$. The camera was calibrated on a blackbody reference. To eliminate the problem of the error on temperature due to uncertainties on the emissivity, the specimen surface was covered with a strongly emissive black paint.

In a second part, fatigue tests (without cooling) are periodically interrupted, and the stress level is increased until the specimen fracture is obtained. Tests were carry out as described in Table 2 and 3. During the last test, with a stress amplitude of $160 \mathrm{MPa}$ (for A42) and $205 \mathrm{MPa}$ (for A48), the temperature rapidly increases until infrared camera saturation and the fatigue machine is stopped automatically because of the high temperature due to the self-heating effect.

Table 2: Interrupted fatigue tests for the A42 steel

\begin{tabular}{|c|c|c|c|c|c|}
\hline Test & Number of cycles & Stress (MPa) & Test & Number of cycles & Stress (MPa) \\
\hline 1 & $1.6 \times 10^{7}$ & 45.7 & 9 & $1.6 \times 10^{7}$ & 102.3 \\
\hline 2 & $1.6 \times 10^{7}$ & 51.2 & 10 & $2 \times 10^{7}$ & 108 \\
\hline 3 & $1.6 \times 10^{7}$ & 56.8 & 11 & $2 \times 10^{7}$ & 113.7 \\
\hline 4 & $1.6 \times 10^{7}$ & 62.5 & 12 & $2 \times 10^{7}$ & 120 \\
\hline 5 & $1.6 \times 10^{7}$ & 68.2 & 13 & $2 \times 10^{7}$ & 130 \\
\hline 6 & $1.6 \times 10^{7}$ & 73.9 & 14 & $2 \times 10^{7}$ & 140 \\
\hline 7 & $1.6 \times 10^{7}$ & 79.6 & 15 & $2 \times 10^{7}$ & 150 \\
\hline 8 & $1.6 \times 10^{7}$ & 85.3 & 16 & $2 \times 10^{7}$ & 160 \\
\hline
\end{tabular}


Table 3: Interrupted fatigue tests for the A48 steel

\begin{tabular}{|c|c|c|c|c|c|}
\hline Test & Number of cycles & Stress (MPa) & Test & Number of cycles & Stress (MPa) \\
\hline 1 & $2 \times 10^{7}$ & 56 & 9 & $2 \times 10^{7}$ & 145 \\
\hline 2 & $2 \times 10^{7}$ & 65.6 & 10 & $2 \times 10^{7}$ & 155 \\
\hline 3 & $2 \times 10^{7}$ & 74.4 & 11 & $2 \times 10^{7}$ & 165 \\
\hline 4 & $2 \times 10^{7}$ & 85.4 & 12 & $2 \times 10^{7}$ & 185 \\
\hline 5 & $2 \times 10^{7}$ & 94.6 & 13 & $2 \times 10^{7}$ & 195 \\
\hline 6 & $2 \times 10^{7}$ & 105 & 14 & $2 \times 10^{7}$ & 205 \\
\hline 7 & $2 \times 10^{7}$ & 116 & 15 & $2 \times 10^{7}$ & 205 \\
\hline 8 & $2 \times 10^{7}$ & 125 & & & \\
\hline
\end{tabular}

\section{Results}

\section{Mechanical results}

The Yield Stress and the Ultimate Tensile Strength are respectively 309 and $508 \mathrm{MPa}$ for A48 steel, and 285 and $455 \mathrm{MPa}$ for the A42 steel. Due to the higher content of solute atoms for the A48 steel, the tensile strength is higher. Due to the same reason, the S-N curve (Fig. 4) for the A48 steel is above the A42 S-N curve, and the A48 fatigue limit is higher than A42 fatigue limit. For the Ultimate tensile Strength, the difference between the two steels is about $10 \%$, in good agreement with the difference in the fatigue limit at $10^{7}$ cycles (about $11 \%$ ). Between $10^{6}$ and $10^{9}$ cycles, a slight decrease of the stress amplitude is visible for the two steels.

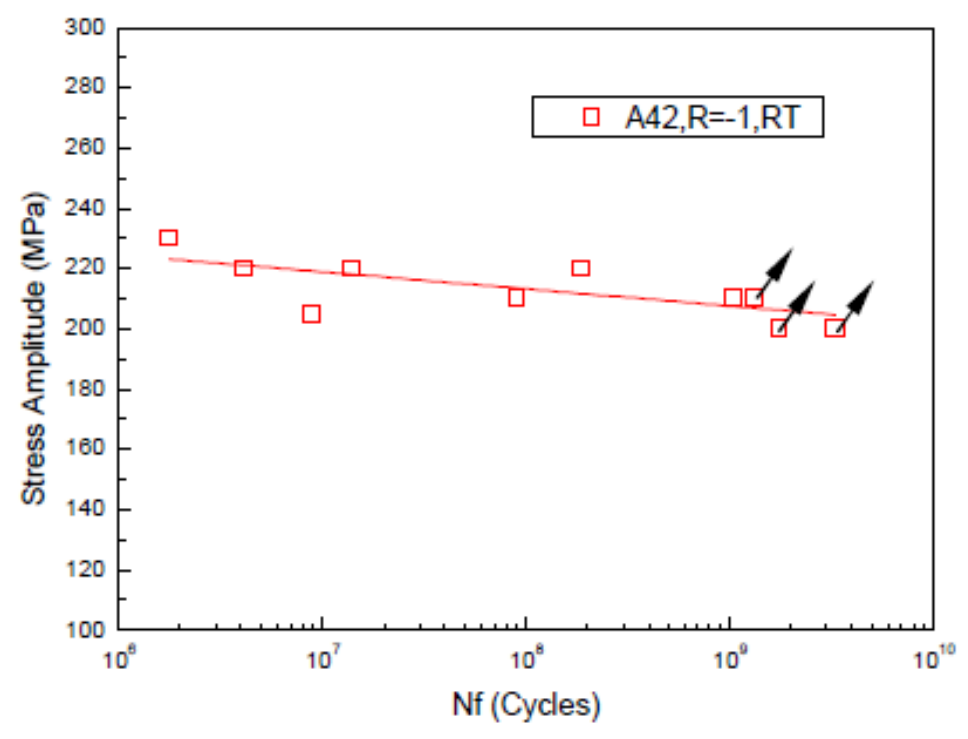




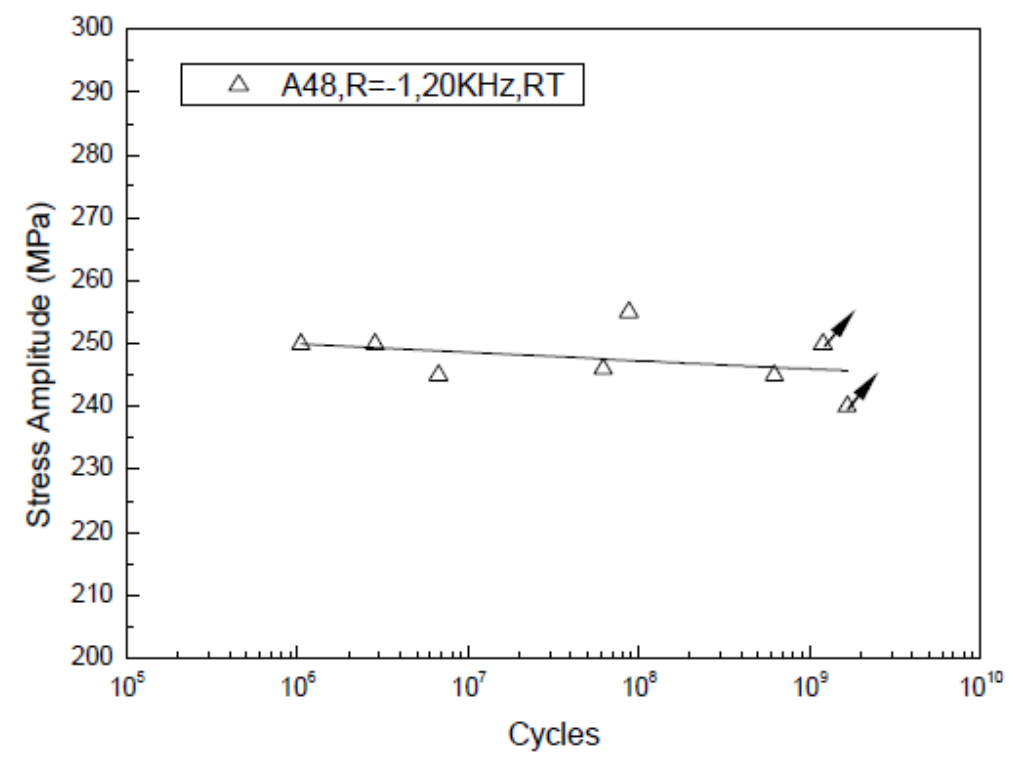

Fig. 4: Stress-Number of cycles curves for the A42 and A48 Steels

\section{Thermal results}

The temperature evolutions measured in the center of the specimen during the interrupted tests are given Figs. 5 and 6.

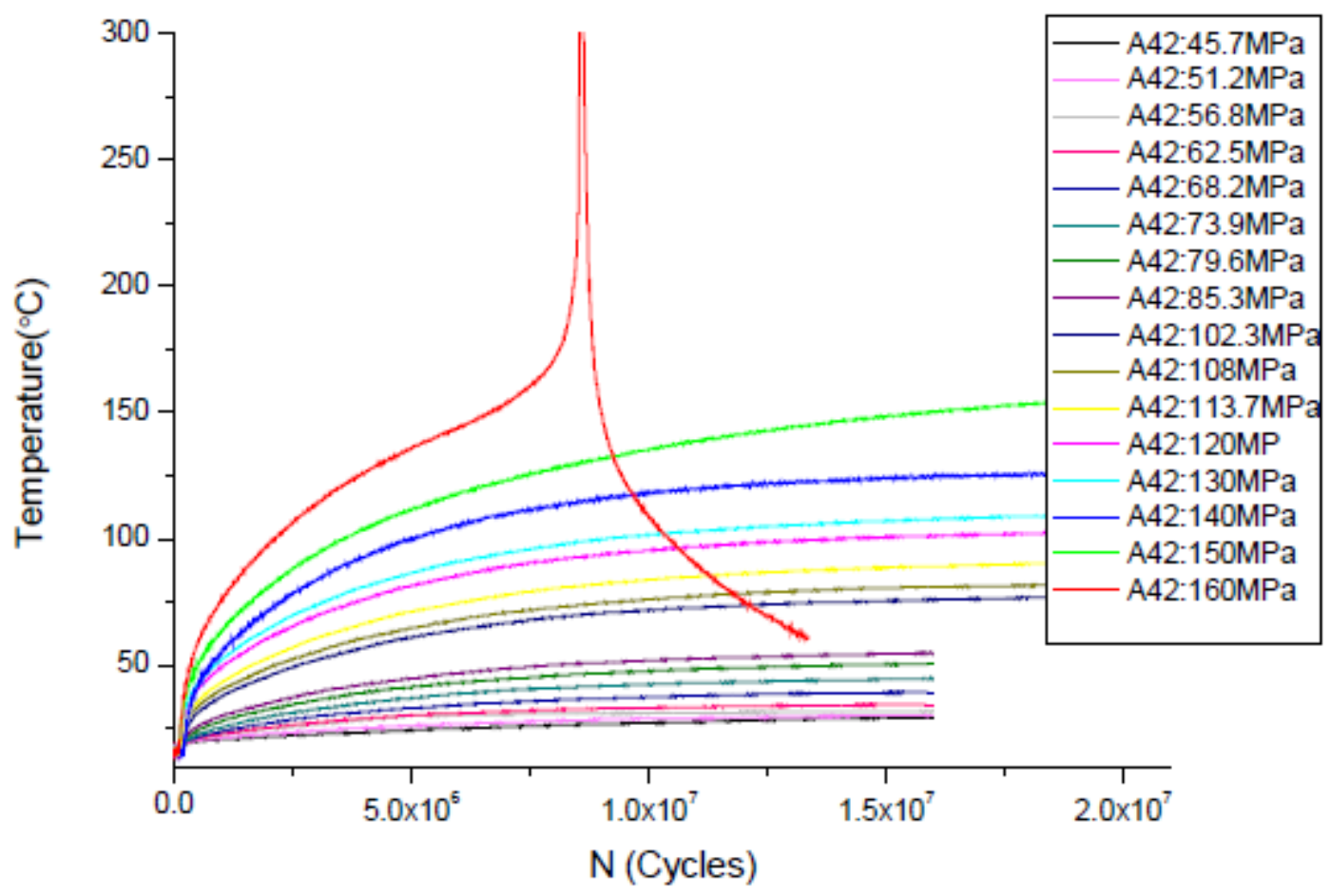

Fig. 5: Temperature evolution during interrupted tests for A42 steel 


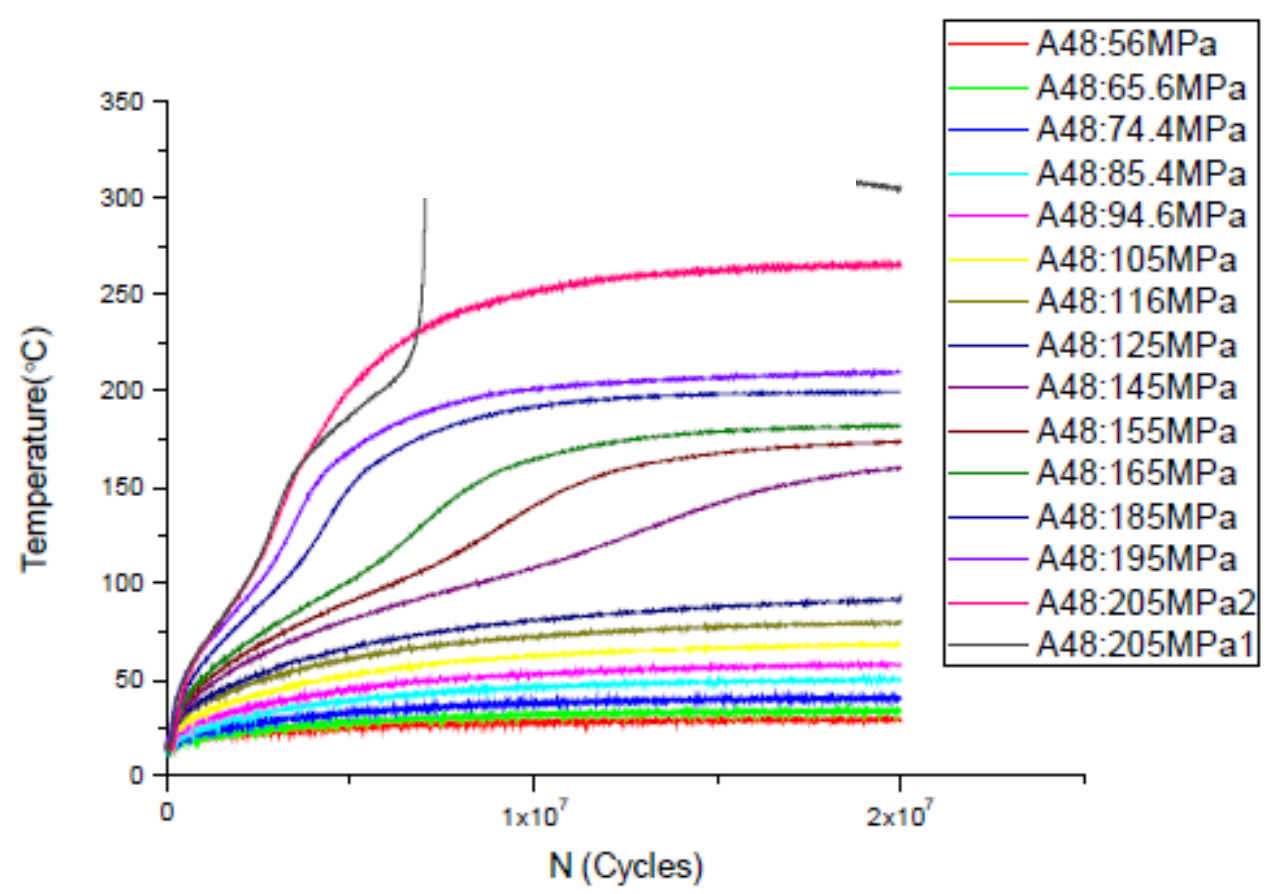

Fig. 6: Temperature evolution during interrupted tests for A48 steel

At the beginning of the fatigue test, the temperature increases and then stabilizes (for the lowest stress amplitudes), or increases slightly (for the higher stress amplitudes). As reported previously [3], higher the stress amplitude level, higher the temperature field on the specimen surface is. When the test is conducted until fracture, after the temperature plateau, the temperature increases rapidly corresponding to the fatigue crack propagation $[5,15]$.

At low stress amplitudes, the temperature rises similarly for A42 and A48 steels. At higher stress amplitudes, the behavior for the two steels is different. For the A48 steel, the curve presents a temperature increase with two regimes. The second regime appears for a temperature around $100^{\circ} \mathrm{C}$ or above.

\section{Discussion}

As reported previously [2], the dissipative heat sources (leading to the temperature increase) is related to the dislocation gliding in the well oriented grains giving the Persistent Slips Bands on the specimen surface. Easier the dislocation gliding, higher the dissipative heat sources are and higher the surface temperature is.

As for the internal friction tests, during cyclic fatigue tests, the carbon and nitrogen atoms redistribution between octahedral sites in the ferritic lattice occurs (Snoek Peak). This mechanism results also in dissipative heat sources as well as the solute atoms dragging by the dislocations (Cold Work Peak) during the dislocations gliding.

Regarding Fig 2 the inverse of the quality factor $Q^{-1}$ of the Snoek Peak is higher than Cold Work Peak and only the first mechanism will be consider in the following. From the quality factor, is it possible to quantify the dissipated energy during one cycle:

$$
\Delta W=2 \pi Q^{-1} W
$$


With $\quad W=\frac{\sigma^{2}}{2 E}$ the maximal elastic storage energy during one cycle and $\sigma$ and $E=210 \mathrm{GPa}$ respectively the stress amplitude and the Young modulus.

From the curve of Fig 2, a maximum value of the inverse of the quality factor $\Delta / 2=1.41 \times 10^{-3}$ can be evaluated. At ambient temperature, the relaxation time $\tau=\frac{1}{2 \pi f}=0.11 \mathrm{~s}$ can be deduced from the internal friction test frequency $f=1.5 \mathrm{~Hz}$.

At a frequency of $20 \mathrm{kHz}$ and for ambient temperature, the inverse of the quality factor can be calculated from the following equation [16]:

$$
Q^{-1}(\omega)=\Delta \frac{\omega \tau}{1+\omega^{2} \tau^{2}}
$$

With $\omega$ the circular frequency. In the case of the Snoek Peak $Q^{-1}=2.04 \times 10^{-7}$ is obtained. For a stress amplitude of $200 \mathrm{MPa}$, a dissipated energy per cycle $\Delta W$ of $2.08 \times 10^{-1} \mathrm{~J} / \mathrm{m}^{3}$ is found from equation (1).

The heat equation allows to estimate the associated temperature increment $\theta_{s}$ reached after the transient regime:

$$
\theta_{s}=\frac{\tau_{t h} f_{F} \Delta W}{\rho C}
$$

With $\tau_{\mathrm{th}}=30 \mathrm{~s}$ the characteristic time of heat losses, $f_{F}=20 \mathrm{kHz}$ the fatigue test frequency, $\rho=7800 \mathrm{~kg} \cdot \mathrm{m}^{-3}$ the density and $C=460 \mathrm{Jkg}^{-1} \mathrm{~K}^{-1}$ the heat capacity.

The numerical application gives $\theta_{s}=0.035 \mathrm{~K}$ which is negligible. The major part of the dissipative heat sources are thus due to the dislocations gliding.

The main difference between the two steels is the nitrogen and carbon solute content in the lattice, which is high for the A48 steel, and very low for the A42 steel. The dislocations anchorage is much important by solute atoms than by precipitates [17].

As illustrated by the Fig. 7, at the beginning of the fatigue test (for a same stress), the solute atoms interact with the mobile dislocations in the A48 steel (as seen by the occurrence of the Cold Work Peak) whereas in the A42 steel no solute atoms interact with the mobile dislocations (no Cold Work Peak). So, in the A48 steel, the dislocations gliding is reduced leading to a reduction of dissipative heat sources and so a reduced increase in temperature (compared to A42 steel).
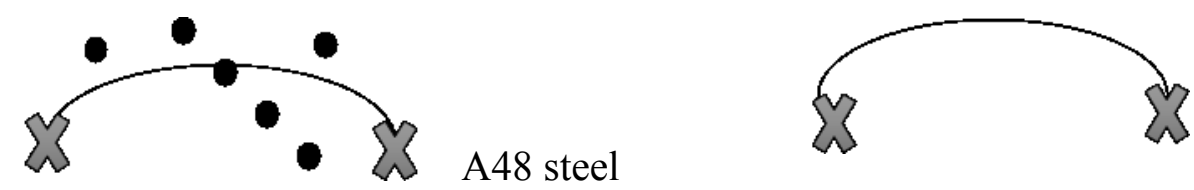

A42 steel

Fig.7: Illustration of the different dislocation gliding for the two steels

Wilson and Troman [18] have performed fatigue tests on a C-Mn steel (with $0.029 \%$ of carbon, $0.003 \%$ of nitrogen) after recrystallization at $710^{\circ} \mathrm{C}$ followed by either transferred to a furnace at $400^{\circ} \mathrm{C}$ and furnace cooled to $150^{\circ} \mathrm{C}$ over a period of 12 hours or brine quenched. Fatigue tests were made at four temperatures $\left(20,60,90,130^{\circ} \mathrm{C}\right)$ at a frequency of $5 \mathrm{~Hz}$. The number of cycles at failure was in the range $10^{4}$ to $10^{6}$ cycles which corresponds to the High Cycle Fatigue domain. For the quenched steel, where carbon and nitrogen were certainly free in the lattice, the number of active slips bands after fatigue has decreased compared to the annealed steel. If the number of active slips bands decreases, it means that the dislocation gliding is impeded by the solute atoms. These authors have performed Transmission Electron Microscopy (TEM) investigations below the surface where active slip bands occur. In quenched specimens, that had been fatigued to failure, dense dislocations 
clouds dominated. Arrays of carbide precipitations have formed in most of the regions of low dislocations density. For specimens fatigued at $60^{\circ} \mathrm{C}$ or above, well defined channels were seen that were free from small precipitates and contained few dislocations. Such clear channels are believed to be zones of high amplitudes dislocations movement (active slips bands). Some of the dislocations near the edges and ends of active slip bands nucleated precipitates that grew abnormally during continued cycling. After prolonged cycling at $90^{\circ} \mathrm{C}$, a small proportion of the precipitates in these sites had grown to form platelets up to more $1 \mu \mathrm{m}$ diameter (platelet identified as cementite by electron diffraction). Precipitates nucleation occurs within the envelopes of low amplitudes dislocation that surround the active bands. The most favorable regions, for precipitate formations on dislocations during fatigue, are those in which dislocations movements are small and dislocations densities are not too high. These authors show a decrease of the solute atoms during cycling at a temperature above $60^{\circ} \mathrm{C}$ by formation of precipitates.

So, the dislocations gliding must be easier after cycling leading to an evolution of the solute atoms decrease. It must note that Wilson et al. have performed their tests in the High Cycle Fatigue domain ( $\mathrm{HCF}, 10^{4}$ to $10^{6}$ cycles) at a low frequency $(5 \mathrm{~Hz})$.

C. Wang [19] in his $\mathrm{PhD}$ thesis performed tensile tests on an Armco iron before and after fatigue tests (at $20 \mathrm{kHz}$ until $1.6 \times 10^{9}$ cycles). After the fatigue test, a decrease of the Yield Stress happens which was attributed to a probably reorganization of the solute atoms during the test. Unfortunately, there is no TEM observations on specimens failed in the VHCF domain at $20 \mathrm{kHz}$ for steels in the literature.

Another reason, is that during fatigue tests, the C-Mn steels (and more particularly A48 steel) show a work hardening behavior at the beginning of the fatigue tests inducing a higher dislocation density. Due to the temperature increase during the test, the diffusion of free solute atoms (for A48 steel) is accelerated. Nitrogen and carbon atoms segregates on new dislocations leading to a less content of free solute atoms in the lattice and so, the density of anchored dislocations decreases. The number of mobile dislocations increases, and so the dissipative heat sources increase which also can explain for the A48 steel the second temperature increase. For the A42 steel, there was no free solute atoms in the lattice and the number of mobile dislocations is practically unchanged.

\section{Conclusion}

In this study, interrupted fatigue tests on two C-Mn steels different by the free solute content in the lattice were performed in the Very High Cycle Fatigue domain. During the tests, the temperature field was recorded on the specimen surface thanks to an infrared camera. The temperature evolution during the test was different between the two steels.

For the A42 steel with very few solute atoms in the lattice, after the beginning of the test, the temperature is stable or slightly increases. For the A48 steel with higher free solute atoms in the lattice, the temperature increase is reduced compared to the A42 steel. This feature is attributed to the strong anchorage of the dislocations which reduces the dislocation gliding and the dissipative heat sources. During the tests, two mechanisms, precipitates formation and/or work hardening, conduct to a solute atoms redistribution allowing for the A48 steel an easier dislocation gliding and more dissipative heat sources and a temperature increase on the specimen surface.

An important point to highlight (shown by the mechanical tests) is the increase of the fatigue limit between $10^{6}$ to $10^{9}$ cycles for A48 steel compared to A42 steel due to the free solute atoms in the lattice which anchors the dislocations even at $20 \mathrm{kHz}$ (corresponding to a strain rate of around $100 \mathrm{~s}^{-}$ $1)$. 


\section{References}

[1] C. Wang, D. Wagner, C. Bathias - Fatigue crack initiated from PSB at VHCF in Iron, International Congress on Fracture, Beijing, Chine, 16-21 juin 2013

[2] C. Wang, A. Blanche, D. Wagner, A. Chrysochoos, C. Bathias, Dissipative and microstructural effects associated with fatigue crack initiation on an Armco iron, Int. Jl fatigue, 58 (2014) 152-157

[3] D. Wagner, N. Ranc, C. Bathias, P.C. Paris, Fatigue crack initiation detection by an infrared thermography method, Fat. Fract. Engng Mater Struct 33 (2009)12-21

[4] D. Wagner, N. Ranc, Self heating of materials during mechanical solicitations: a mean to understand the damage mechanism. SEM Fall Conference and International Symposium on Intensive loading and its effects, 19-22 oct 2014, Beijing, Chine

[5] C. Wang, D. Wagner, C. Bathias - Study of fatigue crack mechanism on an armco iron in the gigacycle fatigue by temperature recording and microstructural observations, International Congress on Fracture, Beijing, Chine, 16-21 juin 2013

[6] D. Wagner, J.C. Moreno, C. Prioul, Vieillissement dynamique dans les joints soudés d'aciers au $\mathrm{C}-\mathrm{Mn}$ : influence de quelques paramètres métallurgiques sur le comportement en traction, Revue de Métallurgie-CIT/SGM, 12 (décembre 2000)1481-1500.

[7] D. Wagner, J.C. Moreno, C. Prioul, Dynamic Strain Aging Sensitivity of Heat Affected Zones in C-Mn Steels, J. of Nucl. Mat., Volume 252-3 (février 1998) 257-265.

[8] L. Chen, N.M. Van der Pers, A. Bottger, Th.H. De Keijser, E.J. Mittemeijer, Lattice changes of iron-nitrogen martensite on ageing at room temperature, Met. Trans.A, 21A (1990) 2857-2867.

[9] L. Chen, N.M. Van der Pers, A. Bottger, Th.H. De Keijser, E.J. Mittemeijer, Lattice changes of iron-carbon martensite on ageing at room temperature, Met. Trans.A, 22A (1991) 1957-1967

[10] L. Chen, A. Bottger, E.J. Mittemeijer, Tempering of iron-carbon-nitrogen martensites, Met. Trans.A, 23A (1992) 1129-1145

[11] P. Fergusson, K.H. Jack, Quench ageing and strain ageing of nitrogen ferrite. Proc Heat Treatment Conf., Ed. The Metals Society, Birmingham (1981) 158

[12] D. Wagner, N. Roubier, C. Prioul, Measurement of sensitivity to dynamic strain aging in C-Mn steels by internal friction method, Mat. Sc and Technology, Vol 22-3(2006) 301-307.

[13] J. D. Fast, Mét. Cor. Ind. 435, (1961) 383

[14] C. Bathias, P.C. Paris, Gigacycle fatigue in mechanical practice. Marcel Dekker, New York, (2005).

[15] N. Ranc, D. Wagner, P.C. Paris, Study of thermal effects associated with crack propagation during very high cycle fatigue, Acta Materiala 56 (2008) 4012-4021.

[16] M.S. Blanter, I.S. Golovin, H. Neuhäuser, H.R. Sinning, Internal Friction in Metallic Materialsa Handbook, Springer, Berlin, 2007 
[17] B. Jaoul, Etude de la plasticité et application aux métaux, Mines Paris Tech Les Presses, Paris, 2008

[18] D.V. Wilson, J.K. Tromans, Effect of strain ageing on fatigue damage in low carbon steel,Acta Met. 18 (1970) 1197-1208

[19] C. Wang, $\mathrm{PhD}$ Thesis, Microplasticité et dissipation en fatigue à très grand nombre de cycles du fer et de l'acier, 7 juin 2014,Université Paris Ouest, France 